OPEN ACCESS

Edited by:

Qi Meng,

Harbin Institute of Technology, China

Reviewed by:

Boya Yu,

Beijing Jiaotong University, China

Xiaodong Lu,

Dalian University of Technology, China

Tin Oberman,

University College London,

United Kingdom

${ }^{*}$ Correspondence:

Yan Wang

wang.y@tcu.edu.cn

Specialty section:

This article was submitted to

Environmental Psychology,

a section of the journal

Frontiers in Psychology

Received: 29 July 2021 Accepted: 15 December 2021

Published: 11 January 2022

Citation:

Cai C, XU YN, Wang Y, Wang QK and Liu L (2022) Experimental Study

on the Effect of Urban Road Traffic

Noise on Heart Rate Variability

of Noise-Sensitive People.

Front. Psychol. 12:749224.

doi: 10.3389/fpsyg.2021.749224

\section{Experimental Study on the Effect of Urban Road Traffic Noise on Heart Rate Variability of Noise-Sensitive People}

\author{
Chao Cai, Yanan Xu, Yan Wang*, Qikun Wang and Lu Liu \\ School of Architecture, Tianjin Chengjian University, Tianjin, China
}

Epidemiological studies have confirmed that long-term exposure to road traffic noise can cause cardiovascular diseases (CDs), and when noise exposure reaches a certain level, the risk of related CDs significantly increases. Currently, a large number of Chinese residents are exposed to high noise exposure, which could greatly increase the risk of cardiovascular disease. On the other hand, relevant studies have found that people with high noise sensitivity are more susceptible to noise. And it is necessary to pay more attention to the high noise-sensitive people. This study investigated the acute physiological effect of different noise-sensitive groups by indoor-level noise stimulus experiments under laboratory conditions, by observing heart rate variability (HRV) indicators, including standard deviation of NN intervals $(\mathrm{SDNN})$, low frequency/high frequency $(\mathrm{LF} / \mathrm{HF})$, and heart rate $(\mathrm{HR})$. The results showed that (a) there was no significant difference in HRV between the high-sensitive group and the low-sensitive group at the physiological baseline and the different stimulating noise levels. (b) Then, based on the theory of cumulative effect of noise proposed by WHO Regional Office for Europe, non-significant but observable differences between groups were further discussed. By analyzing differences of the variation trends and the within-group significant changes of SDNN and HR between the two groups, the results tended to show that the high-sensitive group is more affected by road traffic noise. In addition, the values of SDNN and HR showed observable between-group differences at $55 \mathrm{~dB}(\mathrm{~A})$ and $65 \mathrm{~dB}(\mathrm{~A})$ which corresponding to the SPL associated with a significantly increased risk of cardiovascular disease concerned by epidemiological studies. According to the cumulative effect theory $(\mathrm{WHO})$, these differences in HRV caused by short-term noise stimulation may have the potential to produce physiological response and lead to between-groups differences in prevalence after long-term recurrent effect, and deserve attention and further research.

Keywords: road traffic noise, noise sensitivity, indoor-level noise, heart rate variability, acute physiological effect 


\section{INTRODUCTION}

Road traffic noise is one of the causative factors for cardiovascular diseases (CDs) confirmed by numerous studies (Babisch, 2011; Basner et al., 2014). According to the previous research conclusions of noise exposure limits, a considerable number of residents in Chinese cities are exposed to high risk noise environment, facing the greater risks of $\mathrm{CDs}$ (Hu et al., 2019). Meanwhile, because high-noise sensitive people are more susceptible to noise, showing a higher level of psychological and physiological influence than others (Persson et al., 2007), the physiological effects of noise related to CDs in this population should be concerned and studied.

Nowadays, the exposure of urban road traffic noise in China is relatively severe (Yang, 2020), which has reached or exceeded the noise control recommendations proposed by relevant studies. According to the China Environmental Noise Prevention and Control Annual Report of the Ministry of Ecology and Environment of the People's Republic of China (2019), from 2015 to 2019, the $L_{\mathrm{d}}{ }^{1}$ of road traffic noise in cities nationwide was $66.8 \mathrm{~dB}(\mathrm{~A})$ to $67.1 \mathrm{~dB}(\mathrm{~A})$, and the $L_{\mathrm{d}}$ in first-tier cities was higher, reaching at $68.5 \mathrm{~dB}(\mathrm{~A})$ to $68.9 \mathrm{~dB}(\mathrm{~A})$. For another, previous epidemiological studies have preliminarily confirmed that long-term exposure to road traffic noise mainly causes CDs (Sørensen et al., 2013; Basner and McGuire, 2018), especially the daytime noise exposure (WHO Regional Office for Europe, 2018b). And some conclusions have shown that the risk of CDs significantly increases when $L_{\text {den }}$ is higher than $55 \mathrm{~dB}(\mathrm{~A})$ or $60 \mathrm{~dB}(\mathrm{~A})$ (Bluhm and Eriksson, 2011). For the sake of protecting human health, World Health Organization (WHO) proposed the noise limit $\left(L_{\mathrm{den}}\right)$ of $53 \mathrm{~dB}(\mathrm{~A})$ in 2018. However, due to the lack of relevant researches in China, especially in the face of the poor road traffic noise environment, more attention should be paid to the impact of road traffic noise on Chinese people.

Different noise-sensitive people are affected differently by noise. As an independent personality trait and a potential variable of individual, noise sensitivity plays a key role in studies on noise annoyance and noise-induced health deterioration (Smith, 2003), and has been gradually paid attention to in studies of the noise impact on the public as an observing factor (van Kamp and Davies, 2013). Previous epidemiological and physiology-psychology studies have found that compared with low-noise sensitive people, high-noise sensitive people have higher subjective annoyance (Jong and Jin, 2011), higher perceived stress (Fyhri and Aasvang, 2010), while worse sleep quality (Halonen et al., 2012) and lower cognitive level (Wright et al., 2014). And physiologically, high-noise sensitive people are at higher risk of CDs (Babisch et al., 2009; Berry and Flindell, 2009; Ndrepepa and Twardella, 2011). These studies indicate that physiological effects of noise are related to noise sensitivity, and more attention should be paid to high-noise sensitive people.

Besides, the relevant research methods of acute effect is available to explore the physiological effects of noise, which is conducive to the observation of indicator variation trend

${ }^{1}$ Only $L_{\mathrm{d}}$ is available in the China Environmental Noise Prevention and Control Annual Report. and sensitivity differences in short period (Buccelletti et al., 2009; Lee et al., 2010). For example, numerous researchers have found physiological trends in CDs [through heart rate variability (HRV) indicators] with noise exposure in short-term strong noise stimulation studies (Lusk et al., 2004; Björ et al., 2007; Haralabidis et al., 2008; Dirk et al., 2010). Meanwhile, HRV is often used as a physiological indicator reflecting cardiovascular disease in the noise evaluation of physiological effects, which is an effective indicator to judge and predict cardiovascular diseases in medicine and is reliable physiological parameters to measure the physiological stress state of the human body under noise environment (Lan, 2010). Overall, HRV, as a physiological indicator suitable for observing short-term noise stimulation, is available for this study.

Thus this study focused on the cardiovascular effects of road traffic noise induced in noise-sensitive people through short-term noise stimulation experiment in laboratory, and compared and discussed the physiological effect of noise between high-sensitive groups and low-sensitive groups.

\section{MATERIALS AND METHODS}

The noise stimuli experiments were carried out in a semianechoic laboratory, with the HRV index measures as the experimental physiological indicators. According to WHO Regional Office for Europe (2018a), chronic CDs are primarily associated with sustained daytime noise exposure, this study explored the influence of noise on subjects in the daytime awake state. The reading state was taken as the test state, and neutral and calm current events were selected as reading materials, in order to minimize the influence of non-experimental factors on the study. A repeated-measures ANOVA was used to analyze the data of the indicators to determine the physiological effect of road traffic noise on people with different noise sensitivities.

\section{Experimental Factor and Levels}

The experimental factor was the sound pressure level (SPL), using $L_{\text {Aeq }}$ as the corresponding evaluating indicator. Due to the majority of road traffic noise complaints occurred inside buildings according to the China Environmental Noise Prevention and Control Annual Report, this study focused on the physiological effect of noise under the indoor environment. The exposure SPL levels in this study were set to match the following

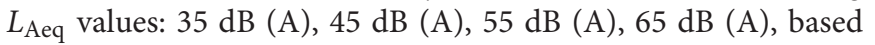
on the field measured data of indoor SPL $\left[L_{\mathrm{d}, \max }=62.4 \mathrm{~dB}(\mathrm{~A})\right.$ and $\left.L_{\mathrm{d}, \min }=33.7 \mathrm{~dB}(\mathrm{~A})\right]$ and the laboratory background SPL [15.7 $\mathrm{dB}(\mathrm{A})$, set as the physiological resting state SPL level]. The experimental noise signals were live audio recordings, and played by Adobe Audition CC2019, JTS-PA150 audio power amplifier, JTSY-omnidirectional sound source which is passive speaker (Beijing J.T Technology Co., Ltd.), and the audio interface is bayonet nut connector (BNC).

Noise signal recording and indoor SPL testing were performed in a typical frontage residential unit with the window opened. The test site is located at an urban expressway in Tianjin, China, which have eight-lane in both directions, with an average daily traffic flow of 86,940 vehicles, including 15,395 heavy vehicles. 
The noise signals were recorded by Roland R44 with Rode NTG-3 microphone ( 1 channel, 24 bit rate, $96 \mathrm{kHz}$ sampling frequency), then through the distortion degree analysis, the signals with distortion degree less than 3\% were selected (Xie, 2006). After modulating the SPL by spectraLAB, the final experimental noise signals were made $(89.14 \%$ low-frequency energy, nonstationary noise). Due to the focus on the physiological effects of SPL factors, noise spectrum and other characteristics were not considered in this study.

\section{Experimental Observation Indicators}

Heart rate variability, as a reliable physiological parameters to measure the physiological stress state of human body under noise environment, were selected as the experimental observation indicators in this study, included time domain parameter [Standard Deviation of $\mathrm{NN}$ intervals (SDNN)], frequency domain parameter [Low Frequency/High Frequency (LF/HF)], and Heart Rate (HR). Among them, the SDNN is stable and has a good correlation in the repeat evaluation (HRV Cooperation Study Group, 2000). LF/HF is a valid evaluation index of increased sympathetic activity and decreased parasympathetic activity, and has been widely used in related studies.

This research adopted the ErgoLAB Man-MachineEnvironment Testing Cloud Platform V3.0 (Kingfar International Inc., Beijing, China) to record the physiological indicators. And that includes the design module of ErgoLAB V3.0, ECG sensors from the wearable physiological recording system, and analysis modules for HRV, which is used to process data.

\section{Experimental Subjects and Noise Sensitivity Grouping}

College students were selected for this study who are convenient for experimental observation as the experimental subjects, because they are relatively healthy and have no cardiovascular diseases compared with other age groups in the adult population. A total of 30 college students were randomly selected as the experimental subjects (mean age of $23.1 \pm 1.41$ years; 17 male and
13 female). No subjects had past medical history of CDs and all subjects had normal basic hearing. Before the experiment, noise sensitivity of all subjects were collected by the Weinstein Noise Sensitivity scale (Zhong et al., 2018; Moghadam et al., 2021), noise sensitivity grouping was performed according to the scale score. And cluster analysis revealed a noise sensitivity grouping value of 69 points $(p=0.000)$. Fifteen subjects with scores $\geq 69$ were classified as the high-sensitivity group, and fifteen subjects with scores $\leq 68$ were classified as the low-sensitivity group.

\section{Experimental Process Control}

To reduce the experimental error as much as possible, the following measures were taken to control the experimental procedure.

\section{Experimental Steps and Duration}

The main steps of the formal experiment were as follows (Figure 1):

(1) On the day of the experiment, participants arrived early at the laboratory to make relevant preparations before the experiment, including wearing physiological sensor, gradually adapting to the environment, and stabilizing their emotions. This process lasted for $30 \mathrm{~min}$.

(2) Without playing any experimental noise signal, the physiological data of the subjects in the resting state were recorded for $10 \mathrm{~min}$.

(3) In the formal noise exposure experiment, physiological data of the stress state were collected and recorded during exposure to experimental noise signals of different SPL levels that were randomly played one by one. The noise exposure lasted for $10 \mathrm{~min}$, and the interval between two stimuli was $5 \mathrm{~min}$. The relevant time length was set according to the following bases:

- The basis for setting the duration of a single noise exposure.

A report published by the WHO Regional Office for Europe (WHO Regional Office for Europe, 2018a) showed that acute physiological effects can occur within seconds or minutes from

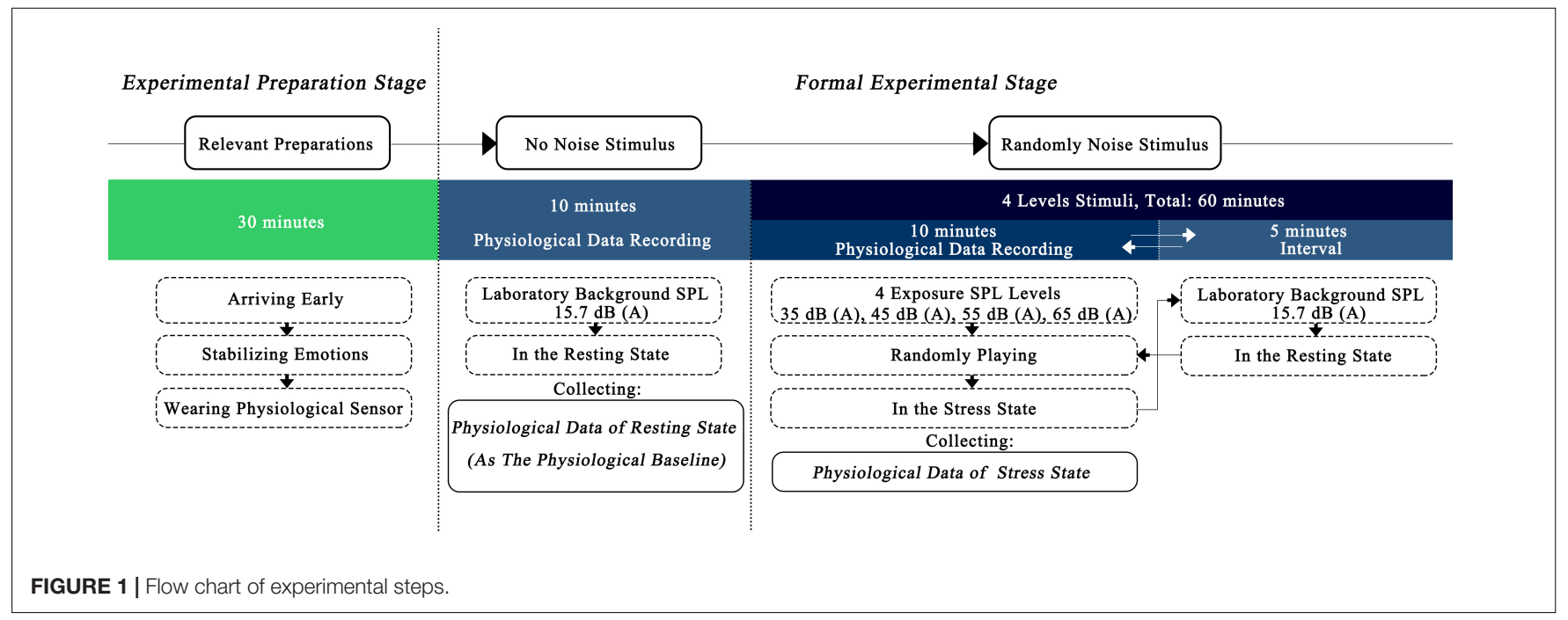


the initiation of a noise stimulus. In addition, in the relevant research of acute effect, lower SPL levels have been studied with noise exposure duration of mostly 10-20 min (Walker et al., 2016), while higher noise exposure duration was mostly 5-10 min (Kraus et al., 2013; El Aarbaoui et al., 2017). Therefore, the duration of a single noise exposure was set to $10 \mathrm{~min}$.

- The basis for setting the duration of the interval between two noise stimuli.

The pre-experiment found that the HRV indicators, gradually stabilized between 3 and $5 \mathrm{~min}$ after exposure to noise. Therefore, the interval between two noise stimuli was set to $5 \mathrm{~min}$.

\section{Experimental Environment Control}

The experimental environment control included the following three main aspects:

(1) The noise exposure experiments were completed in a semi-anechoic laboratory, which can meet the demand for playback of low SPL level noise signals.
(2) The light and thermal environment of the laboratory were strictly controlled to ensure that the relevant environmental parameters were maintained at comfort psychological and physiological levels. The horizontal illumination of the desktop on which to complete reading tasks was set at 735 Lux, the air temperature was around $25^{\circ} \mathrm{C}$, and the relative humidity of the air was $50-60 \%$.

(3) The experiment-related equipment was placed outside the laboratory to avoid disturbance to the subjects by the sound of operating the equipment and experimenter activity. The physiological data were collected through wearable sensors and wirelessly transmitted to the recording (Figure 2).

\section{Experimental Subject Control}

The following measures were also taken to avoid unnecessary psychological fluctuations:

(1) One week before the formal experiment, subjects familiarized themselves with the laboratory environment, and explanations about the experimental process were provided.

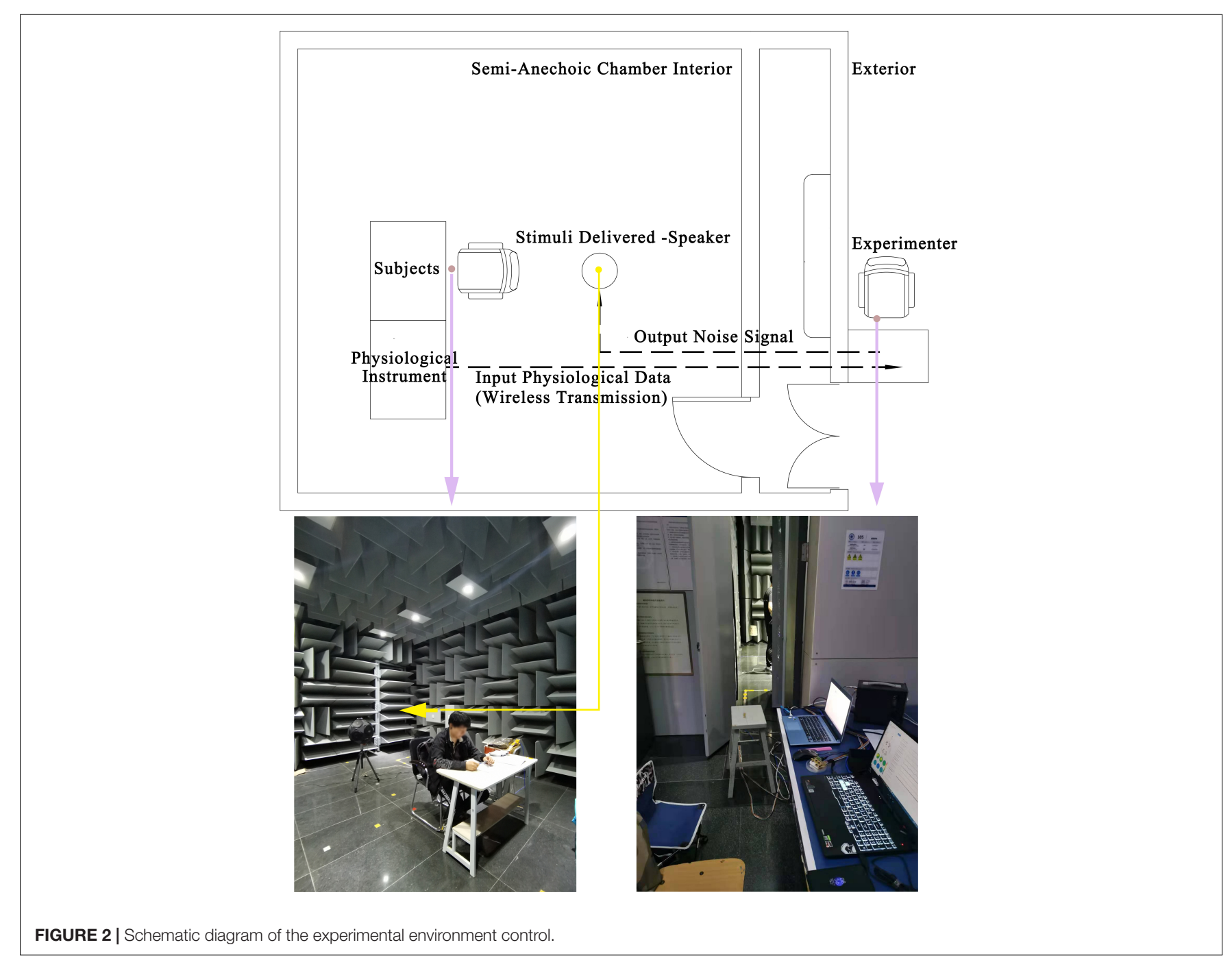


(2) One day before the formal experiment, subjects were asked not to drink alcohol, tea, coffee, or other caffeinated beverages, and to ensure that they had sufficient sleep the night before the experiment.

(3) Half an hour before the formal experiment, subjects were asked not to perform strenuous exercise and to arrive at the laboratory in advance to prepare and adapt to the environment.

\section{RESULTS}

\section{The Differences in Significance of Heart Rate Variability Between Noise-Sensitive Groups}

Figure 3 shows the distributions of HRV with the stimulating SPL changing in the high-sensitive group and the low-sensitive group, including the value of maximum, minimum, median, quartile, mean and other information. And the result of one-sample Kolmogorov-Smirnov test (Table 1) showed that the distribution of observed physiological data of all experimental samples met the normal distribution. Then the result of the further repeatedmeasures ANOVA (Table 2) showed that the $p$-values of all HRV indicators were greater than 0.05 , indicating that there was no significant difference in HRV between the two noisesensitive groups under short-term noise stimulation. This result has two implications: First, there were no significant differences in physiological baseline ${ }^{2}$ of the SDNN, LF/HF, and HR between two groups. Second, there were no significant differences in the SDNN, LF/HF, and HR responses to the same level of noise stimulus between two groups.

The results of non-significant differences between groups were inconsistent with the conclusions of previous relevant studies. And the possible reasons for these results will be analyzed and discussed in the section "Non-significant Difference Between Noise-Sensitive Groups" of this manuscript.

${ }^{2}$ The physiological data measured at resting state (under $15.7 \mathrm{~dB}$ ) were taken as the physiological baseline.
TABLE 1 | One-sample Kolmogorov-Smirnov test results.

\begin{tabular}{lccccc}
\hline SDNN & $15.7 \mathrm{~dB}$ & $35 \mathrm{~dB}$ & $45 \mathrm{~dB}$ & $55 \mathrm{~dB}$ & $65 \mathrm{~dB}$ \\
Exact sig. (two-tailed) & 0.505 & 0.290 & 0.429 & 0.810 & 0.716 \\
LF/HF & $15.7 \mathrm{~dB}$ & $35 \mathrm{~dB}$ & $45 \mathrm{~dB}$ & $55 \mathrm{~dB}$ & $65 \mathrm{~dB}$ \\
Exact sig. (two-tailed) & 0.693 & 0.312 & 0.852 & 0.791 & 0.842 \\
HR & $15.7 \mathrm{~dB}$ & $35 \mathrm{~dB}$ & $45 \mathrm{~dB}$ & $55 \mathrm{~dB}$ & $65 \mathrm{~dB}$ \\
Exact sig. (two-tailed) & 0.916 & 0.713 & 0.933 & 0.984 & 0.519 \\
\hline
\end{tabular}

TABLE 2 | The repeated-measures ANOVA results.

\begin{tabular}{lccc}
\hline & SDNN & LF/HF & HR \\
\hline$F$ & 0.056 & 1.613 & 0.147 \\
Sig. & 0.814 & 0.214 & 0.705 \\
\hline
\end{tabular}

$p>0.05$, no significant difference.

\section{Variation Trend of Heart Rate Variability in the High-Sensitive Group Standard Deviation of NN Intervals}

The variation trend of SDNN in the high-sensitive group with SPL is shown in Figure 4. With the increase of SPL, SDNN generally presented an upward trend. The SDNN increased significantly from $15.7 \mathrm{~dB}(\mathrm{~A})$ to $45 \mathrm{~dB}(\mathrm{~A})$, and this upward trend eased off from $45 \mathrm{~dB}(\mathrm{~A})$ to $65 \mathrm{~dB}$ (A), with slight fluctuations. The maximum value of SDNN offset to the baseline appeared at $65 \mathrm{~dB}(\mathrm{~A})$. The repeated-measures ANOVA result of SDNN for the main effect of SPL was $p=0.043$, and the corresponding results of pairwise comparison (Table 3 ) revealed that the SDNN only showed a significant difference between $45 \mathrm{~dB}$ (A) and $15.7 \mathrm{~dB}(\mathrm{~A})(p<0.05)$.

\section{Low Frequency/High Frequency}

The variation trend of LF/HF in the high-sensitive group (Figure 4) showed that LF/HF gentle increase at first and then decreased with the increase of SPL. The LF/HF increased obviously from $35 \mathrm{~dB}(\mathrm{~A})$ to $55 \mathrm{~dB}(\mathrm{~A})$, and the maximum value of $\mathrm{LF} / \mathrm{HF}$ offset to the baseline occurred at $55 \mathrm{~dB}(\mathrm{~A})$. The Mauchly's test of sphericity of LF/HF $(p=0.010<0.05)$ did not obey the

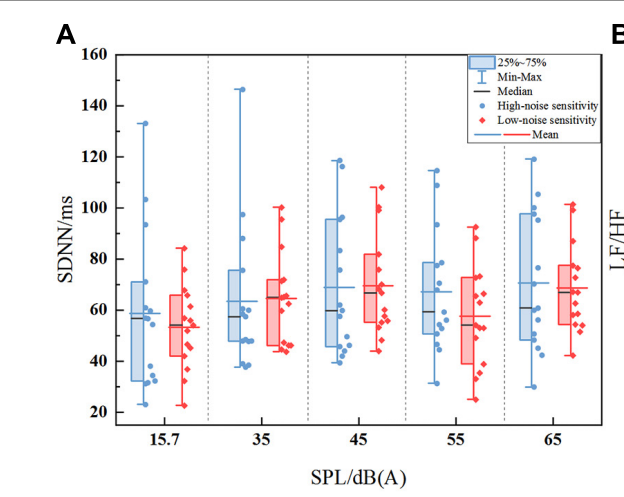

SDNN

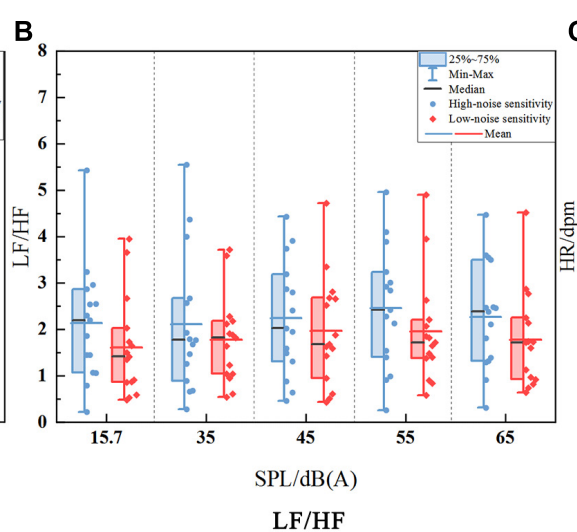

LF/HF

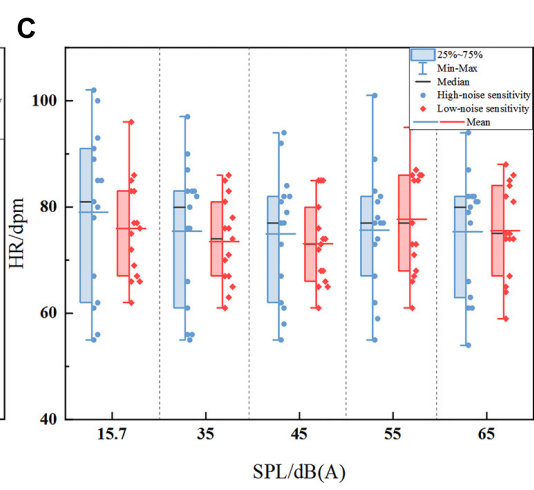

HR

FIGURE 3 | The distribution of HRV indicators of the subjects in different noise-sensitive groups. (A) The distribution of SDNN in different noise-sensitive groups. (B) The distribution of LF/HF in different noise-sensitive groups. (C) The distribution of HR in different noise-sensitive groups. 


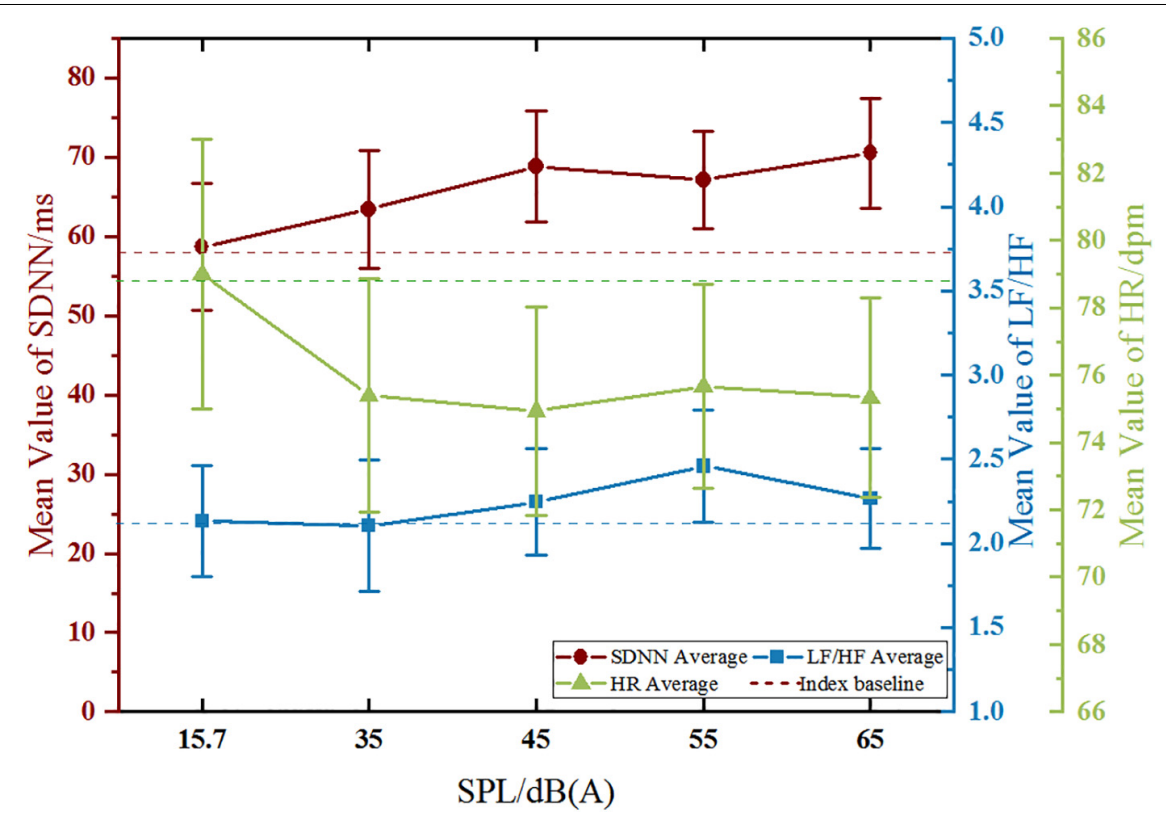

FIGURE 4 | Variation trend of HRV with SPL in the high-sensitive group.

TABLE 3 | High-sensitive group's SDNN/ms pairwise comparisons.

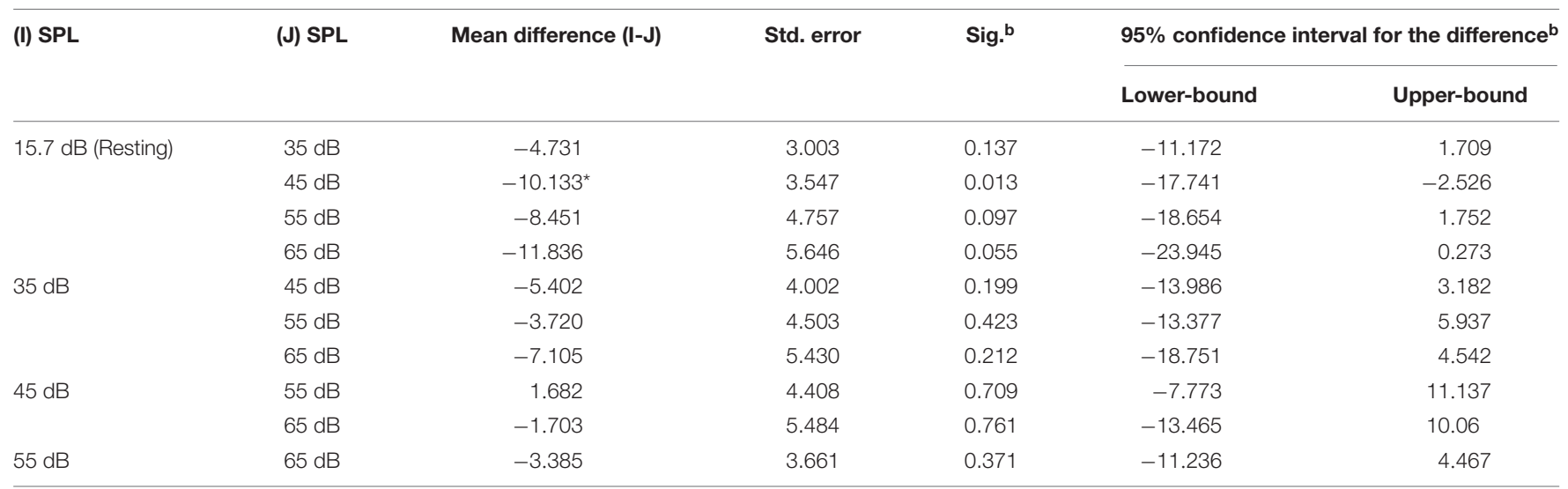

Mauchly's test of sphericity $p=0.257>0.05$ obeyed the hypothesis of a spherical distribution, and the tests of within-subjects effects was $p=0.043<0.05$.

Based on estimated marginal means.

*The mean difference was significant at the 0.05 level.

${ }^{b}$ Adjustment for multiple comparisons: Least Significant Difference (equivalent to no adjustments).

hypothesis of spherical distribution, and the further multivariate test was $p=0.939$, which indicated that there was no significant difference in LF/HF between the different SPL levels.

\section{Heart Rate}

The variation trend of HR in the high-sensitive group (Figure 4) showed a general downward trend with the increase of SPL, whereby HR decreased significantly from $15.7 \mathrm{~dB}(\mathrm{~A})$ to $35 \mathrm{~dB}$ (A), and this downward trend began to plateau from $35 \mathrm{~dB}$ (A) to $65 \mathrm{~dB}(\mathrm{~A})$, with slight fluctuations. The maximum value of $\mathrm{HR}$ offset to the baseline appeared at $45 \mathrm{~dB}$ (A). The repeated-measures ANOVA result of $\mathrm{HR}$ for the main effect of SPL was $p=0.050$, and the corresponding results of pairwise comparison (Table 4) revealed that HR showed significant differences between $35 \mathrm{~dB}(\mathrm{~A}), 45 \mathrm{~dB}(\mathrm{~A})$, and $15.7 \mathrm{~dB}$ (A) $(p<0.05)$.

\section{Variation Trend of Heart Rate Variability in the Low-Sensitive Group \\ Standard Deviation of NN Intervals}

The variation trend of the SDNN in the low-sensitive group with SPL is shown in Figure 5. With the increase of SPL, the SDNN generally showed an upward trend. The SDNN increased significantly from $15.7 \mathrm{~dB}(\mathrm{~A})$ to $45 \mathrm{~dB}(\mathrm{~A})$, and this upward trend eased off from $45 \mathrm{~dB}(\mathrm{~A})$ to $65 \mathrm{~dB}(\mathrm{~A})$, with a more obvious decline at $55 \mathrm{~dB}(\mathrm{~A})$. The maximum value of the SDNN offset to the baseline appeared at $45 \mathrm{~dB}(\mathrm{~A})$. The 
TABLE 4 | High-sensitive group's HR/bpm pairwise comparisons.

\begin{tabular}{|c|c|c|c|c|c|c|}
\hline \multirow[t]{2}{*}{ (I) SPL } & \multirow[t]{2}{*}{ (J) SPL } & \multirow[t]{2}{*}{ Mean difference (I-J) } & \multirow[t]{2}{*}{ Std. error } & \multirow[t]{2}{*}{ Sig. ${ }^{b}$} & \multicolumn{2}{|c|}{$95 \%$ confidence interval for the difference ${ }^{b}$} \\
\hline & & & & & Lower-bound & Upper-bound \\
\hline \multirow[t]{4}{*}{15.7 dB (Resting) } & $35 \mathrm{~dB}$ & $3.600^{*}$ & 1.129 & 0.007 & 1.179 & 6.021 \\
\hline & $45 \mathrm{~dB}$ & $4.067^{*}$ & 1.152 & 0.003 & 1.595 & 6.539 \\
\hline & $55 \mathrm{~dB}$ & 3.333 & 2.670 & 0.232 & -2.394 & 9.060 \\
\hline & $65 \mathrm{~dB}$ & 3.667 & 2.203 & 0.118 & -1.059 & 8.392 \\
\hline \multirow[t]{3}{*}{$35 \mathrm{~dB}$} & $45 \mathrm{~dB}$ & 0.467 & 0.888 & 0.608 & -1.439 & 2.372 \\
\hline & $55 \mathrm{~dB}$ & -0.267 & 2.159 & 0.903 & -4.897 & 4.364 \\
\hline & $65 \mathrm{~dB}$ & 0.067 & 1.551 & 0.966 & -3.259 & 3.392 \\
\hline \multirow[t]{2}{*}{$45 \mathrm{~dB}$} & $55 \mathrm{~dB}$ & -0.733 & 2.161 & 0.739 & -5.369 & 3.902 \\
\hline & $65 \mathrm{~dB}$ & -0.400 & 1.650 & 0.812 & -3.939 & 3.139 \\
\hline $55 \mathrm{~dB}$ & $65 \mathrm{~dB}$ & 0.333 & 1.027 & 0.750 & -1.869 & 2.535 \\
\hline
\end{tabular}

Mauchly's test of sphericity $p=0.000<0.05$ did not obey the hypothesis of spherical distribution, and the multivariate test results was $p=0.050$.

Based on estimated marginal means.

*The mean difference was significant at the 0.05 level.

${ }^{b}$ Adjustment for multiple comparisons: Least Significant Difference (equivalent to no adjustments).

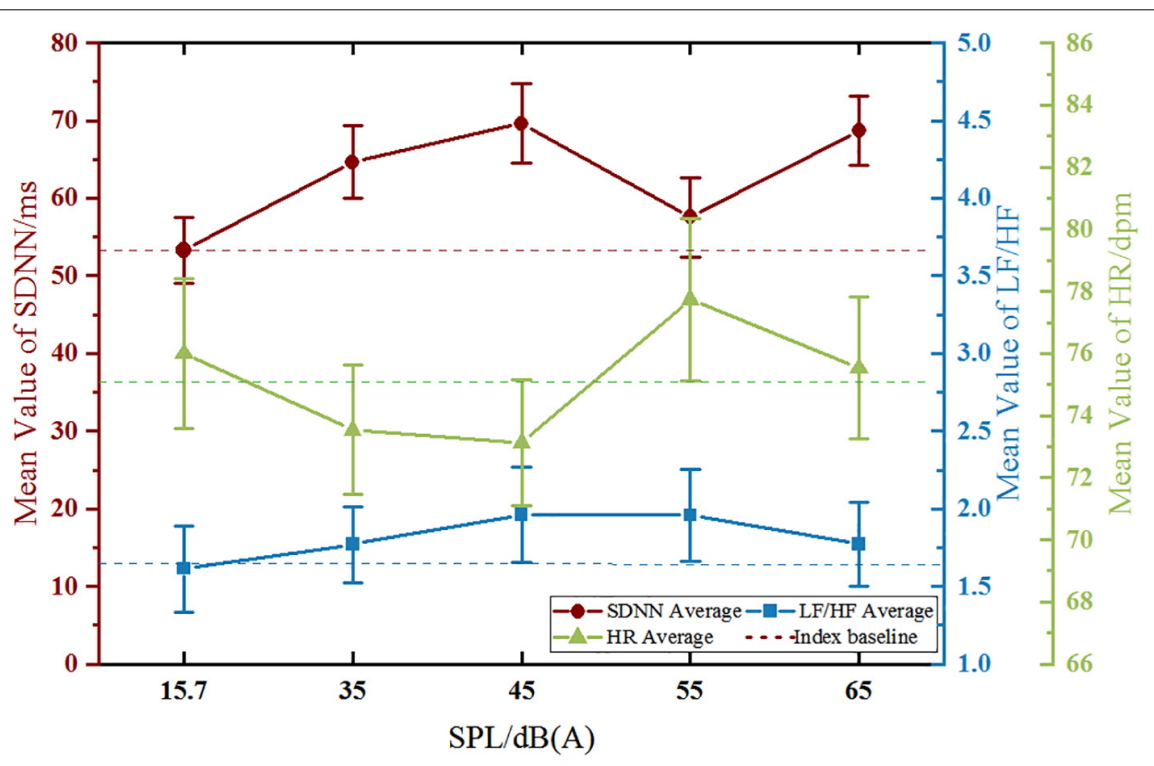

FIGURE 5 | Variation trend of HRV with SPL in the low-sensitive group.

repeated-measures ANOVA result of SDNN for the main effect of SPL was $p=0.004$, and the corresponding results of pairwise comparison (Table 5) revealed that significant differences in the SDNN were found between $35 \mathrm{~dB}(\mathrm{~A}), 45 \mathrm{~dB}(\mathrm{~A}), 65 \mathrm{~dB}$ $(\mathrm{A})$, and $15.7 \mathrm{~dB}(\mathrm{~A})(p<0.01)$, as well as between $45 \mathrm{~dB}$ (A), $65 \mathrm{~dB}(\mathrm{~A})$, and $35 \mathrm{~dB}(\mathrm{~A})(p<0.05)$, between $55 \mathrm{~dB}(\mathrm{~A})$ and $45 \mathrm{~dB}(\mathrm{~A})(p<0.05)$, and between $65 \mathrm{~dB}(\mathrm{~A})$ and $55 \mathrm{~dB}$ (A) $(p<0.05)$.

\section{Low Frequency/High Frequency}

The variation trend of LF/HF in the low-sensitive group (Figure 5) revealed that $\mathrm{LF} / \mathrm{HF}$ increased at first and then decreased with the increase of SPL. The LF/HF increased obviously from $15.7 \mathrm{~dB}(\mathrm{~A})$ to $45 \mathrm{~dB}(\mathrm{~A})$, and the $\mathrm{LF} / \mathrm{HF}$ values of $45 \mathrm{~dB}(\mathrm{~A})$ and $55 \mathrm{~dB}(\mathrm{~A})$ were similar, reaching a maximum offset to the baseline. The Mauchly's test of sphericity of LF/HF $(p=0.010<0.05)$ did not obey the hypothesis of spherical distribution, and the further multivariate test was $p=0.412$, which indicates that there was no significant difference in LF/HF between the different SPL levels.

\section{Heart Rate}

The variation trend of HR in the low-sensitive group (Figure 5) revealed a general decrease at first and then an increase with the increase of SPL, whereby HR decreased obviously from $15.7 \mathrm{~dB}$ (A) to $45 \mathrm{~dB}(\mathrm{~A})$, and significantly fluctuated from $45 \mathrm{~dB}(\mathrm{~A})$ to $65 \mathrm{~dB}$ (A). The maximum value of $\mathrm{HR}$ offset to the baseline appeared at $45 \mathrm{~dB}(\mathrm{~A})$. The repeated-measures ANOVA result of HR for the main effect of SPL was $p=0.050$, and the corresponding results of pairwise comparison (Table 6) revealed 
TABLE 5 | Low-sensitive group's SDNN/ms pairwise comparisons.

\begin{tabular}{|c|c|c|c|c|c|c|}
\hline \multirow[t]{2}{*}{ (I) SPL } & \multirow[t]{2}{*}{ (J) SPL } & \multirow[t]{2}{*}{ Mean difference (I-J) } & \multirow[t]{2}{*}{ Std. error } & \multirow[t]{2}{*}{ Sig. ${ }^{b}$} & \multicolumn{2}{|c|}{$95 \%$ confidence interval for the difference ${ }^{b}$} \\
\hline & & & & & Lower-bound & Upper-bound \\
\hline \multirow[t]{4}{*}{15.7 dB (Resting) } & $35 \mathrm{~dB}$ & $-11.341^{\star}$ & 3.120 & 0.003 & -18.033 & -4.650 \\
\hline & $45 \mathrm{~dB}$ & $-16.343^{*}$ & 3.352 & 0.000 & -23.533 & -9.154 \\
\hline & $55 \mathrm{~dB}$ & -4.248 & 3.659 & 0.265 & -12.095 & 3.599 \\
\hline & $65 \mathrm{~dB}$ & $-15.360^{\star}$ & 3.424 & 0.001 & -22.704 & -8.016 \\
\hline \multirow[t]{3}{*}{$35 \mathrm{~dB}$} & $45 \mathrm{~dB}$ & $-5.002^{*}$ & 1.877 & 0.019 & -9.028 & -0.976 \\
\hline & $55 \mathrm{~dB}$ & 7.093 & 5.248 & 0.198 & -4.163 & 18.350 \\
\hline & $65 \mathrm{~dB}$ & -4.019 & 3.651 & 0.290 & -11.849 & 3.812 \\
\hline \multirow[t]{2}{*}{$45 \mathrm{~dB}$} & $55 \mathrm{~dB}$ & $12.095^{\star}$ & 4.994 & 0.030 & 1.384 & 22.807 \\
\hline & $65 \mathrm{~dB}$ & 0.983 & 3.620 & 0.790 & -6.782 & 8.748 \\
\hline $55 \mathrm{~dB}$ & $65 \mathrm{~dB}$ & $-11.112^{*}$ & 2.771 & 0.001 & -17.055 & -5.169 \\
\hline
\end{tabular}

Mauchly's test of sphericity $p=0.001<0.05$, which did not obey the hypothesis of spherical distribution, and the multivariate test result was $p=0.004<0.05$.

Based on estimated marginal means.

*The mean difference was significant at the 0.05 level.

${ }^{b}$ Adjustment for multiple comparisons: Least Significant Difference (equivalent to no adjustments).

TABLE 6 | Low-sensitive group's HR/bpm pairwise comparisons.

\begin{tabular}{|c|c|c|c|c|c|c|}
\hline \multirow[t]{2}{*}{ (I) SPL } & \multirow[t]{2}{*}{ (J) SPL } & \multirow[t]{2}{*}{ Mean difference (I-J) } & \multirow[t]{2}{*}{ Std. error } & \multirow[t]{2}{*}{ Sig. ${ }^{b}$} & \multicolumn{2}{|c|}{$95 \%$ confidence interval for the difference ${ }^{b}$} \\
\hline & & & & & Lower-bound & Lower-bound \\
\hline \multirow[t]{4}{*}{15.7 dB (Resting) } & $35 \mathrm{~dB}$ & 2.467 & 1.272 & 0.073 & -0.261 & -0.261 \\
\hline & $45 \mathrm{~dB}$ & 2.867 & 1.737 & 0.121 & -0.859 & -0.859 \\
\hline & $55 \mathrm{~dB}$ & -1.733 & 2.892 & 0.559 & -7.937 & -7.937 \\
\hline & $65 \mathrm{~dB}$ & 0.467 & 2.065 & 0.824 & -3.963 & -3.963 \\
\hline \multirow[t]{3}{*}{$35 \mathrm{~dB}$} & $45 \mathrm{~dB}$ & 0.400 & 1.154 & 0.734 & -2.075 & -2.075 \\
\hline & $55 \mathrm{~dB}$ & -4.200 & 2.187 & 0.075 & -8.891 & -8.891 \\
\hline & $65 \mathrm{~dB}$ & -2.000 & 1.298 & 0.146 & -4.785 & -4.785 \\
\hline \multirow[t]{2}{*}{$45 \mathrm{~dB}$} & $55 \mathrm{~dB}$ & $-4.600^{\star}$ & 2.042 & 0.041 & -8.980 & -8.980 \\
\hline & $65 \mathrm{~dB}$ & $-2.400^{*}$ & 1.018 & 0.033 & -4.583 & -4.583 \\
\hline $55 \mathrm{~dB}$ & $65 \mathrm{~dB}$ & 2.200 & 1.455 & 0.153 & -0.920 & -0.920 \\
\hline
\end{tabular}

Mauchly's test of sphericity $p=0.001<0.05$, which did not obey the hypothesis of spherical distribution, and the multivariate test result was $p=0.050$.

Based on estimated marginal means.

*The mean difference was significant at the 0.05 level.

${ }^{b}$ Adjustment for multiple comparisons: Least Significant Difference (equivalent to no adjustments).

that $\mathrm{HR}$ was significantly different between $55 \mathrm{~dB}(\mathrm{~A}), 65 \mathrm{~dB}(\mathrm{~A})$, and $45 \mathrm{~dB}(\mathrm{~A})$ (all, $p<0.05)$.

\section{ANALYSIS AND DISCUSSION}

\section{Non-significant Difference Between Noise-Sensitive Groups}

According to the results presented in section "The Differences in Significance of Heart Rate Variability Between Noise-Sensitive Groups," the HRV indicators, including SDNN, LF/HF, and HR, did not differ significantly between the high-sensitive group and the low-sensitive group under short-term noise stimulation in this study. And these result are not consistent with the conclusions of previous relevant studies. In the chronic noisephysiological effect studies, cross-sectional studies of long-term exposure to traffic noise (mainly airport noise) (Babisch et al., 2009; Shepherd et al., 2010) confirmed that residents with higher noise sensitivity suffer significantly more CDs and sleep disorders than residents with lower noise sensitivity. And in the acute effect studies, Shepherd et al. (2016) confirmed that HRV of 103 subjects showed significant differences in SDNN and HR between different sensitive groups under stimulation of standard digitized sound samples $[70 \mathrm{~dB}(\mathrm{~A})]$ in laboratory. Compared with these studies, firstly, the level of noise in above studies were higher, while this study focuses on the effects of noise below $65 \mathrm{~dB}$ (A). Based on the physiological mechanism for coping with noise (Babisch, 2006; WHO Regional Office for Europe, 2018a), higher SPL stimulation may cause faster physiological feedback. Due to the low SPL $[\leq 65 \mathrm{~dB}(\mathrm{~A})]$ and short duration of noise stimulation $(10 \mathrm{~min})$ in this study, the slow physiological response caused by low SPL noise probably has not reached the adequate degree in a short time, so no significant results were presented. Secondly, compared with Shepherd's study, the state of subjects and duration of noise stimulation during the experiment were similar in this study, but Shepherd chose digital audio 
samples which are different with the real recorded signals using in this study. And the HRV data testing period in Shepherd's study was several seconds after noise exposure, while it was 10 min while noise stimulating in this study. In summary, the non-significance results in this study may be mainly caused by the lower SPL of stimuli noise followed by the characteristics of stimulating noise signals and HRV data testing period.

Although there were no significant differences in HRV of short-term noise stimulation between groups, this study still showed that there were clear differences in variation trend of the physiological indicators with SPL changing between the two sensitive groups. And according to WHO Regional Office for Europe (2018a) relevant theories, the acute biological effects of cardiovascular autonomic arousal do not adapt over time, and that long-term noise exposure can increase the risk of chronic diseases. Based on this theory, it could be inferred that non-significant differences between the two groups may cause distinction on physiology after long-term accumulating, and the details of HRV trends is worth further exploring.

\section{The Differences of Heart Rate Variability Trends Between Noise-Sensitive Groups}

The results (Figure 6) show that there were significant variations just in SDNN and HR with the stimulating SPL changing in the both two groups, while LF/HF showed no significant change among different SPL. Therefore, only the characteristics of trends in SDNN and HR are discussed in this part.

\section{Variation Trend of Standard Deviation of NN Intervals}

Standard deviation of NN intervals showed an upward trend with the increase of SPL in both groups, which is consistent with relevant research conclusions (Kraus et al., 2013; Walker et al., 2016; El Aarbaoui et al., 2017). It follows that, in this study, under the influence of indoor-level road traffic noise, the higher SPL is, the higher SDNN value is. As we know, higher SPL has a greater impact on human body, confirmed by epidemiological studies on the chronic effects of noise, which shown that prevalence rate of CDs of residents living in high noise exposure environment for a long time was significantly higher than those living in quiet areas (Nassur et al., 2019). So it follows that higher SDNN value is detrimental to human physiological health. From this point of view, SDNN of the high-sensitive group was obviously higher than that of the low-sensitive group under $55 \mathrm{~dB}(\mathrm{~A})$ and $65 \mathrm{~dB}$ (A) SPL, which the numerical difference was $9.595 \mathrm{~ms}$ and $1.868 \mathrm{~ms}$, respectively. It can be seen that under the same noise level [55 dB (A) or $65 \mathrm{~dB}(\mathrm{~A})]$, the high-sensitivity group is more affected.

On the other hand, some scholars suggest that rapid physiological responses of low-sensitive people were manifested as strong adaptability to noise (Stansfeld, 1992), and may give rise to the coping mechanism of humans mentioned by WHO which may indirectly reduce the impact of noise on health. In terms of the significance of changes in SDNN within groups, the high-sensitive group just showed a significant change to the baseline at $45 \mathrm{~dB}(\mathrm{~A})$, while the low-sensitive group changed significantly almost with every increase of SPL level. It can be seen that the low-noise sensitive group is more responsive to the change of SPL. Meanwhile, in terms of the degree of deviation from the SDNN baseline, a similar status was observed. At $45 \mathrm{~dB}(\mathrm{~A})(p<0.05)$, there was a increase of $10.133 \mathrm{~ms}$ in the high-sensitive group and a increase of $16.343 \mathrm{~ms}$ in the low-sensitive group. It can be seen that under the same noise stimulus, the physiological feedback of the high-sensitive group was $6.21 \mathrm{~ms}$ slower, and the low-sensitive group also showed stronger response. Based on the analysis of the above two aspects, the low-sensitivity group showed a rapid response in SDNN than the high-sensitivity group. According to the above views of relevant scholars, the high-sensitivity group would be more affected by road traffic noise.

\section{Variation Trend of Heart Rate}

Heart rate showed a downward trend at lower SPL, then leveled off and even increased when SPL is higher than $45 \mathrm{~dB}$ (A) (only in the low-sensitive group showed an upward trend at higher
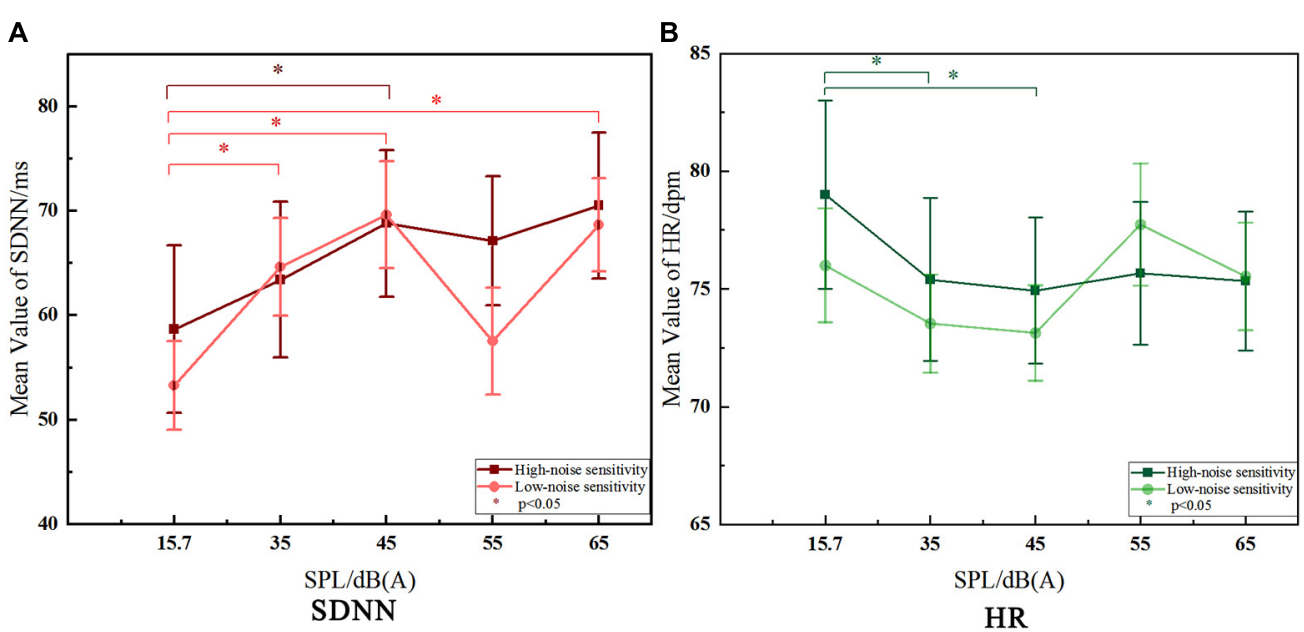

FIGURE 6 | Comparison of the trends of SDNN and HR between noise-sensitive groups. 
SPL). According to Park and Lee (2017), under noise stimulation below $60 \mathrm{~dB}(\mathrm{~A})$, HR decreases in the post-encounter stage due to people's attention being oriented by stimulation (Lang and Bradley, 1997; Boucsein, 2012). After that, when the body reaches the high arousal noise stimulus state, HR presents an upward trend, corresponding to the circa-striker stage. From the above point of view, after significant decrease at $35 \mathrm{~dB}(\mathrm{~A})$ and $45 \mathrm{~dB}(\mathrm{~A})$ compared with the baseline, HR then leveled off in the high-sensitive group. However, the HR in the low-sensitive group increased significantly when SPL was higher than $45 \mathrm{~dB}$ (A), reaching earlier to the upward trend than the high-sensitive group, which is correspond to the circa-striker stage mentioned above. As other studies have shown, HR of the high-sensitive group seemed to be less responsive to different noise stimuli than that of the low-sensitive group (White et al., 2010), and the ability to adapt to noise was also weaker (Stansfeld, 1992). And this is consistent with the result reflected by SDNN.

In terms of $\mathrm{HR}$ value, an epidemiological study of people living with long-term exposure to aircraft noise in west London found that HR value of high-sensitive groups was lower than that of lowsensitive groups (Stansfeld et al., 1985). This study also found a similar trend under the short-term influence of noise, which was lower $2.1 \mathrm{dpm}$ at $55 \mathrm{~dB}(\mathrm{~A})$ and $0.2 \mathrm{dpm}$ at $65 \mathrm{~dB}(\mathrm{~A})$ in $\mathrm{HR}$ of the high-sensitive group than that of the low-sensitive group. At the same time, the above-mentioned $55 \mathrm{~dB}(\mathrm{~A})$ and $65 \mathrm{~dB}(\mathrm{~A})$ (also in the SDNN part) are highly consistent with the SPL findings of epidemiological studies that the prevalence of CDs increasing significantly when the SPL is higher than around $55 \mathrm{~dB}(\mathrm{~A})$ to $60 \mathrm{~dB}$ (A) (Barregard et al., 2009; Bluhm and Eriksson, 2011; Chang et al., 2011). And according to the WHO cumulative effect of noise impact, the differences in HR (and in SDNN) indicators observed in this study caused by short-term noise stimulation may have the potential to produce physiological response and lead to between-groups differences in prevalence after long-term recurrent effect, which is worthy of further research.

\section{CONCLUSION AND PROSPECTS}

In this study, there was no significant difference between sensitive groups in the acute physiological effects of indoor-level traffic noise reflected by observing SDNN, LF/HF, and HR. According to the comparative analysis with the previous research, the possible reasons may be related to the low SPL $[\leq 65 \mathrm{~dB}(\mathrm{~A})]$ of noise concerned in this study, as well as the type of stimulus audio signal and HRV data testing period.

However, according to the theory of cumulative effect of noise proposed by WHO Regional Office for Europe (2018a), we discussed the variation trends and the within-group significant changes of SDNN and HR indicators with SPL, and the results showed that the high-sensitivity group was more affected by road traffic noise. In addition, there are also observable numerical differences in SDNN and HR between the two sensitive groups at the SPL that can significantly increase the prevalence of CDs concerned by epidemiological studies. According to the cumulative effect theory, these non-significant but observable differences in HRV are likely to lead to differences in morbidity between groups, and deserve attention and further research.

In the follow-up study, it is necessary to focus on the residents living on the street for a long time, and the relationship between the acute and chronic noise effects needs to be further discussed by observing the differences between exposed groups and non-exposed groups. For another, the subjects of this study were only college students. Because of the prevalence of CDs would increase with age, middleaged and elderly population should be paid attention to in subsequent studies. In addition, in order to further improve the experiment, the acquisition and playing process of noise signals should be optimized.

\section{DATA AVAILABILITY STATEMENT}

The original contributions presented in the study are included in the article/supplementary material, further inquiries can be directed to the corresponding author/s.

\section{ETHICS STATEMENT}

The studies involving human participants were reviewed and approved by the School of Architecture, Tianjin Chengjian University, Tianjin, China. The patients/participants provided their written informed consent to participate in this study. Written informed consent was obtained from the individual(s) for the publication of any potentially identifiable images or data included in this article.

\section{AUTHOR CONTRIBUTIONS}

CC and YW conceptualized and supervised the project. YNX managed the project and did data analysis and graphs. CC, YNX, and QKW designed the experiments. YNX and QKW carried out the experiments. CC and YNX conceptualized and wrote the first draft of the manuscript. LL made substantial contributions in searching for references. All authors participated in reviewing the manuscript.

\section{FUNDING}

This study was financially supported by the National Natural Science Foundation of China (Grant nos. 51678386 and 51978454) and Tianjin Major Science and Technology Project (18ZXAQSF00120). This study was also supported by the "Scientific Research Support" project provided by Kingfar International Inc.

\section{ACKNOWLEDGMENTS}

The authors thank the research technical and related scientific research equipment support of Kingfar project team. 


\section{REFERENCES}

Babisch, W. (2006). Transportation noise and cardiovascular risk: updated review and synthesis of epidemiological studies indicate that the evidence has increased. Noise Health 8, 1-29. doi: 10.4103/1463-1741.32464

Babisch, W. (2011). Cardiovascular effects of noise. Noise Health 13, 201-204.

Babisch, W., Neuhauser, H., Thamm, M., and Seiwert, M. (2009). Blood pressure of 8-14 year old children in relation to traffic noise at home-Results of the German Environmental Survey for Children (GerES IV). Sci. Total Environ. 407, 5839-5843. doi: 10.1016/j.scitotenv.2009.08.016

Barregard, L., Bonde, E., and Ohrström, E. (2009). Risk of hypertension from exposure to road traffic noise in a population-based sample. Occup. Environ. Med. 66, 410-415. doi: 10.1136/oem.2008.042804

Basner, M., Babisch, W., Davis, A., Brink, M., Clark, C., Janssen, S., et al. (2014). Auditory and non-auditory effects of noise on health. Lancet 383:1325. doi: 10.1016/s0140-6736(13)61613-x

Basner, M., and McGuire, S. (2018). WHO Environmental Noise Guidelines for the European Region: a Systematic Review on Environmental Noise and Effects on Sleep. Int. J. Environ. Res. Public Health 15, 519-545. doi: 10.3390/ ijerph15030519

Berry, B. F., and Flindell, I. H. (2009). Associates Estimating Dose-Response Relationships Between Noise Exposure and Human Health Impacts in the UK. Technical report. London: DEFRA.

Björ, B., Burström, L., Karlsson, M., Nilsson, T., Näslund, U., and Wiklund, U. (2007). Acute effects on heart rate variability when exposed to hand transmitted vibration and noise. Int. Arch. Occup. Environ. Health 81, 193-199. doi: 10. 1007/s00420-007-0205-0

Bluhm, G., and Eriksson, C. (2011). Cardiovascular effects of environmental noise: research in Sweden. Noise Health 13, 212-216. doi: 10.4103/1463-1741.80152

Boucsein, W. (2012). Electrodermal Activity. Berlin: Springer Science \& Business Media.

Buccelletti, E., Gilardi, E., Scaini, E., Galiuto, L., Persiani, R., Biondi, A., et al. (2009). Heart rate variability and myocardial infarction: systematic literature review and metanalysis. Eur. Rev. Med. Pharmacol. Sci. 13, 299-307.

Chang, T.-Y., Liu, C. S., Bao, B. Y., Li, S. F., Chen, T. I., and Lin, Y. J. (2011). Characterization of road traffic noise exposure and prevalence of hypertension in central Taiwan. Sci. Total Environ. 409, 1053-1057. doi: 10.1016/j.scitotenv. 2010.11.039

Dirk, S., Griefahn, B., and Meis, M. (2010). The associations between noise sensitivity, reported physical and mental health, perceived environmental quality, and noise annoyance. Noise Health 12, 7-16. doi: 10.4103/1463-1741. 59995

Fyhri, A., and Aasvang, G. M. (2010). Noise, sleep and poor health: modeling the relationship between road traffic noise and cardiovascular problems. Sci. Total. Environ. 408, 4935-4942. doi: 10.1016/j.scitotenv.2010.06.057

Halonen, J. I., Vahtera, J., Stansfeld, S., Yli-Tuomi, T., Salo, P., Pentti, J., et al. (2012). Associations between nighttime traffic noise and sleep: the Finnish public sector study. Environ. Health Perspect. 120, 1391-1396. doi: 10.1289/ehp. 1205026

Haralabidis, A. S., Dimakopoulou, K., Vigna-Taglianti, F., Giampaolo, M., Borgini, A., Dudley, M. L., et al. (2008). Acute effects of night-time noise exposure on blood pressure in populations living near airports. Eur. Heart J. 29:658. doi: 10.1093/eurheartj/ehn013

HRV Co-operation Study Group (2000). Multicenter-study of HRV's normal field and its reproducibility. Chin. J. Cardiac. Arrhyth. 4, 165-170.

Hu, S. S., Gao, R. L., Liu, L. S., Zhu, M. L., Wang, W., Wang, Y. J., et al. (2019). Summary of the 2018 Report on Cardiovascular Diseases in China. Chin. Circ. J. 34, 209-220.

Jong, K. R., and Jin, Y. J. (2011). Influence of noise sensitivity on annoyance of indoor and outdoor noises in residential buildings. Appl. Acoust. 72, 336-340. doi: 10.1016/j.scitotenv.2016.03.097

Kraus, U., Schneider, A., Breitner, S., Hampel, R., Rückerl, R., Pitz, M., et al. (2013). Individual day-time noise exposure during routine activities and heart rate variability in adults: a repeated measures study. Environ. Health Perspect. 121, 607-612. doi: 10.1289/ehp.1205606

Lan, L. (2010). Mechanism And Evaluation Of The Effects Of Indoor Environmental Quality On Human Productivity. Ph.D. thesis. Shanghai: Shanghai Jiao Tong University.
Lang, P. J., and Bradley, M. M. (1997). "Cuthbert BN. Motivated attention: Affect, activation, and action," in Attention and Orienting: Sensory and Motivational Processes, eds P. J. Lang, R. F. Simons, and M. T. Balaban (Mahwah: Lawrence Erlbaum Associates), 97-135.

Lee, G. S., Chen, M. L., and Wang, G. Y. (2010). Evoked response of heart rate variability using short-duration white noise. Auton. Neurosci. 155, 94-97. doi: 10.1016/j.autneu.2009.12.008

Lusk, S. L., Gillespie, B., Hagerty, B. M., and Ziemba, R. A. (2004). Acute effects of noise on blood pressure and heart rate. Arch. Environ. Health 59, 392-399.

Ministry of Ecology and Environment of the People's Republic of China (2019). China Environmental Noise Prevention and Control Annual Report. Beijing: Ministry of Ecology and Environment of the People's Republic of China.

Moghadam, S. M. K., Alimohammadi, A., Taheri, E., Rahimi, J., Bostanpira, F., and Rahmani, N. (2021). Modeling effect of five big personality traits on noise sensitivity and annoyance. Appl. Acoust. 172, 107655-107656. doi: 10.1016/j. apacoust.2020.107655

Nassur, A. M., Léger, D., Lefèvre, M., Elbaz, M., Mietlicki, F., Nguyen, P., et al. (2019). Effects of Aircraft Noise Exposure on Heart Rate during Sleep in the Population Living Near Airports. Int. J. Environ. Res. Public Health 16, 269-281. doi: 10.3390/ijerph16020269

Ndrepepa, A., and Twardella, D. (2011). Relationship between noise annoyance from road traffic noise and cardiovascular diseases: a meta-analysis. Noise Health 13, 251-259. doi: 10.4103/1463-1741.80163

Park, S. H., and Lee, P. J. (2017). Effects of floor impact noise on psychophysiological responses. Build. Environ. 116, 173-181.

Persson, R., Björk, J., Ardö, J., Albin, M., and Jakobsson, K. (2007). Trait anxiety and modeled exposure as determinants of self-reported annoyance to sound,air pollution and other environmental factors in the home. Int. Arch. Occup. Environ. Health 81, 179-191. doi: 10.1007/s00420-007-0204-1

Shepherd, D., Hautus, M. J., Lee, S. Y., and Mulgrew, J. (2016). Electrophysiological approaches to noise sensitivity. J. Clin. Exp. Neuropsychol. 38, 900-912. doi: 10.1080/13803395.2016.1176995

Shepherd, D., Welch, D., Dirks, K. N., and Mathews, R. (2010). Exploring the relationship between noise sensitivity, annoyance and health-related quality of life in a sample of adults exposed to environmental noise. Int. J. Environ. Res. Public Health 7, 3579-3594. doi: 10.3390/ijerph7103580

Smith, A. (2003). The concept of noise sensitivity: implications for noise control. Noise Health 5, 57-59.

Sørensen, M., Andersen, Z. J., Nordsborg, R. B., Becker, T., Tjønneland, A., Overvad, K., et al. (2013). Long-Term Exposure to Road Traffic Noise and Incident Diabetes: a Cohort Study. Environ. Health Perspect. 121, 217-222. doi: 10.1289/ehp. 1205503

Stansfeld, S. A. (1992). Noise, noise sensitivity and psychiatric disorder: epidemiological and psychophysiological studies. Psychol. Med. 22, 1-44. doi: 10.1017/s0264180100001119

Stansfeld, S. A., Clark, C. R., Turpin, G., Jenkins, L. M., and Tarnopolsky, A. (1985). Sensitivity to noise in a community sample: II: measurement of psychophysiological indices. Psychol. Med. 15, 255-263. doi: 10.1017/ s0033291700023539

El Aarbaoui, T., Méline, J., Brondeel, R., and Chaix, B. (2017). Short-term association between personal exposure to noise and heart rate variability: the RECORD MultiSensor Study. Environ. Pollut. 231, 703-711. doi: 10.1016/j. envpol.2017.08.031

van Kamp, I., and Davies, H. (2013). Noise and health in vulnerable groups: a review. Noise Health 15, 153-159. doi: 10.4103/1463-1741.112361

Walker, E. D., Brammer, A., Cherniack, M. G., Laden, F., and Cavallari, J. M. (2016). Cardiovascular and stress responses to short-term noise exposures-A panel study in healthy males. Environ. Res. 150, 391-397. doi: 10.1016/j.envres. 2016.06.016

White, K., Hofman, W., and van Kamp, I. (2010). "Noise sensitivity in relation to baseline arousal, physiological response and psychological features to noise exposure during task performance," in Proceedings of the Internoise Conference 2010 Lisbon, (Portugal: International Institute of Noise Control Engineering), 3132-3138.

WHO Regional Office for Europe (2018b). Environmental Noise Guidelines For The European Region. Copenhagen: WHO Regional Office for Europe. 
WHO Regional Office for Europe (2018a). Biological Mechanisms Related to Cardiovascular and Metabolic Effects By Environmental Noise. Copenhagen: WHO Regional Office for Europe.

Wright, B., Peters, E., Ettinger, U., Kuipers, E., and Kumari, V. (2014). Understanding noise stress-induced cognitive impairment in healthy adults and its implications for schizophrenia. Noise Health 16, 166-176. doi: 10.4103/14631741.134917

Xie, H. (2006). Research of the Effects of Indoor Noise on Human's Physical Parameters in Street Building. Ph.D. thesis. Chongqing: Chongqing University.

Yang, J. (2020). Research on Road Traffic Noise Pollution and Automatic Monitoring Technology. Chin. Res. Compr. Util. 38, 171-173.

Zhong, T., Chung, P. K., and Liu, J. D. (2018). Short Form of Weinstein Noise Sensitivity Scale (NSS-SF): reliability, Validity and Gender Invariance among Chinese Individuals. Biomed. Environ. Sci. 31, 97-105. doi: 10.3967/bes201 8.012
Conflict of Interest: The authors declare that the research was conducted in the absence of any commercial or financial relationships that could be construed as a potential conflict of interest.

Publisher's Note: All claims expressed in this article are solely those of the authors and do not necessarily represent those of their affiliated organizations, or those of the publisher, the editors and the reviewers. Any product that may be evaluated in this article, or claim that may be made by its manufacturer, is not guaranteed or endorsed by the publisher.

Copyright $\odot 2022$ Cai, Xu, Wang, Wang and Liu. This is an open-access article distributed under the terms of the Creative Commons Attribution License (CC BY). The use, distribution or reproduction in other forums is permitted, provided the original author(s) and the copyright owner(s) are credited and that the original publication in this journal is cited, in accordance with accepted academic practice. No use, distribution or reproduction is permitted which does not comply with these terms. 